\title{
Operative Training in a General Surgery Program: Residents' perspective and analysis of a web-based log-book - Retrospective Cohort Study
}

\section{Felipe Girón Arango}

Universidad del Rosario

\section{Lina Rodriguez}

Universidad de Los Andes

Carlos Rey ( $\nabla$ carlosrey991@gmail.com )

Hospital universitario mayor - Méderi

\section{Marco Vanegas}

Universidad del Rosario

David Venegas

Universidad del Rosario

German Londoño

Universidad del Rosario

Ricardo Nassar

Fundación Santa Fe de Bogotá

Danny Conde

Universidad del Rosario

\section{Research Article}

Keywords: Education, General Surgery, Medical Residency, High-Volume Hospital, Teaching

Posted Date: November 5th, 2021

DOI: https://doi.org/10.21203/rs.3.rs-997274/v1

License: (c) (1) This work is licensed under a Creative Commons Attribution 4.0 International License. Read Full License 


\section{Abstract}

\section{Background}

Surgical education evolves through time, and it's related to the number and type of procedures that residents are exposed to. Hour regulations in resident training affect learning curves, and recording surgical exposure remains to be an effective method to assess and keep track of surgical training. Webbased logbooks have proven to be useful to monitor and follow surgical training in general surgery residents. This study aims to evaluate surgical proficiency in general surgery residents by quantifying their operative exposure and experience by using data collected in a web-based logbook.

Methods

A retrospective study from a prospectively collected data base between September 2018 to September 2019 was performed. All surgery residents were surveyed.

Results

A total of 13160 surgical procedures were performed by residents. Laparoscopic cholecystectomy was the most frequent procedure performed 7404 times (52,6\%), followed by open appendectomy in $34,6 \%$. Trauma context procedures represent $4.9 \%$ of surgical training in our program. Complex procedures such as whipple or distal pancreatectomy represent less than $1 \%$ of the training. $70 \%$ of residents are confident to perform the surgical procedures proposed for their year of residency, $90 \%$ agree that logbooks have a positive impact in their formation.

\section{Conclusion}

Web based logbooks are a feasible method to follow operative experience in general surgery residents, with adequate record of procedures, its complexity, and trauma context. General surgery residents in our program are confident to perform surgical procedures based on the year of residency. Nevertheless, there is no consensus regarding the best way to measure resident experience and meanwhile we keep relying on proxies.

\section{Introduction}

Quality of clinical teaching has been linked to the number and type of patients to which trainees are exposed to [1]. In the same way, surgeons' proficiency has been linked to surgical exposure [2, 3]. To date, various studies have addressed the worldwide concern about the adequacy of operative exposure for surgical residents [4-6]. Current restrictions in resident work hours affect learning curves for even the most common procedures [5]. Hence, it is of paramount importance to appropriately record surgical procedures performed during General Surgery Residency [7]. 
Logbook registry programs constitute a tool to improve surgical exposure with the potential to obtain information on their formation process; it has the objective of simplifying general surgery residents' procedures catalog to obtain reliable records of their academic activities [7]. The analysis of logbooks can reveal weak points of training [8], help in the standardization of clinical training and increase the number of performed procedures by each resident [9]. In the same way, logbooks facilitate communication between the trainee and clinical teacher [10] by aiding the evaluation of whether trainees have fulfilled the minimum requirements of training [11] and identifying strong performers [10]. For all of this, logbooks are widely used to set learning outcomes and to structure and standardize teaching in clinical settings [12] and may benefit designing contextually appropriate surgical training programs [13].

Nowadays, web-based logbooks are widely used in different countries to register their experience [7, 1013] with most of the experience being recorded in British countries [7]. To unify their records and to develop methods that allow surgery residents to reach a basic level of competence, the Surgical Council of Resident Education (SCORE) was developed in 2018 as a guide in residents learning [14]. It measured actual operative experience of graduating residents, classifying the procedures in: Essential Common; Essential Uncommon; and complex procedures [14]. Based on this classification, Bell et al describe that many surgical procedures identified as essential were performed infrequently; and few operations were being done more than 10 times on average during the residency program [14]. This data reflects the concerns about the surgical experience, and volume in the surgical residency programs.

Our aim is to quantify operative exposure and operative experience for surgical technique through data collected in a web-based Logbook, to comprehensively analyze the type and numbers of procedures being performed by a cohort of general surgery residents in Colombia following SCORE in order to provide a worldwide perspective.

\section{Methods}

Following Health Insurance Portability and Accountability Act (HIPAA) guidelines, and Ethical compliance with the Helsinki Declaration, current legislation on research Res. 008430-1993 and Res. 2378-2008 (Colombia) and the International Committee of Medical Journal Editors (ICMJE) were ensured under our Ethics and Research Institutional Committee (IRB) approval.

All Universidad el Rosario general surgery residents were included. This work has been reported in line with the STROCSS criteria.

Surgical skill development, daily surgical experience, procedures, and usefulness of a logbook addressing their surgical training between September 2018 to September 2019 were analyzed. All residents included in the program completed an anonymous survey.

\section{Results}


13.160 surgical procedures were documented. Information was registered by all general surgery residents of Universidad del Rosario, 8 were first year, 9 second year, 5 third year and 7 last year surgery residents. Procedures were categorized according to the Surgical Council on Resident Education (SCORE) in Essential Common, Uncommon and Complex (Table 1). Most complex procedures were performed by third- and fourth-year residents (352 and 571 respectively). A continuum complexity increase during each year was evidenced, from 1 st through last year. The behavior of the complexity versus year of residence can be detailed in the graph 1 .

Table 1

Procedure complexity according to year of residence.

\begin{tabular}{|lllll|}
\hline Year of residence & Complexity & \multicolumn{2}{c|}{ Total } \\
\cline { 2 - 4 } & Essential - Common & Essential - Uncommon & Complex \\
\hline 1 & 3.150 & 318 & 42 & 3510 \\
\hline 2 & 3.289 & 350 & 173 & 3812 \\
\hline 3 & 2.332 & 419 & 352 & 3103 \\
\hline 4 & 1.711 & 453 & 571 & 2735 \\
\hline Total & 10482 & 1540 & 1138 & 13160 \\
\hline
\end{tabular}

Laparoscopic cholecystectomy was the most frequently performed procedure (7404) equivalent to $56.2 \%$ of surgeries, followed by open appendectomy and laparoscopic appendectomy representing $34.7 \%$ and $14 \%$, respectively. Other procedures with a significant volume in our program were open cholecystectomy, colonic resections, gastrectomy's, and bile duct explorations, with percentages of 12.3, 5.59, 4.89 and $3.6 \%$ respectively (Table 2). Major procedures related to hepatobiliary surgery, such as distal pancreatectomies and Whipple procedures, are less frequent, in the order of 0.1 and $0.4 \%$. 
Table 2

Type and total procedures.

\begin{tabular}{|ll|}
\hline Type of procedure & Total procedures (\%) \\
\hline Lap. Cholecystectomy & $7404(56)$ \\
\hline Open Cholecystectomy & $1620(12,31)$ \\
\hline Lap. Appendectomy & $1848(14,04)$ \\
\hline Appendectomy & $4576(34,7)$ \\
\hline Common Bile Duct Exploration & $474(3,6)$ \\
\hline Colonic resections & $736(5,5)$ \\
\hline Gastric resections & $644(4,8)$ \\
\hline Distal pancreatectomy & $16(0,1)$ \\
\hline Whipple procedure & $59(0,4)$ \\
\hline Trauma Surgery & Total \\
\hline Pericardial Window & $48(8,1)$ \\
\hline Modified Neck dissection & $14(2,3)$ \\
\hline Thoracostomy & $128(21,6)$ \\
\hline Exploratory Thoracotomy & $57(9,6)$ \\
\hline Cervicotomy & $10(1,6)$ \\
\hline Laparotomy & $67(11,3)$ \\
\hline
\end{tabular}

Additional classification was performed in terms of the scenario of the procedure in: trauma related, and non-trauma related. A total of 591 procedures were performed in a trauma scenario (firearm projectile or sharp weapon), that amount represents $4.49 \%$ of the surgical training in our program. Most of the traumatic context procedures were performed by first year residents (307), being closed thoracostomies, the predominant surgical procedure performed (Table 3). Procedure's complexity according to SCORE was analyzed in terms of the trauma scenario revealing that most procedures were considered as common and only $4.3 \%$ as complex (Table 4). 
Table 3

Trauma procedures according year of residence

\begin{tabular}{|llll|}
\hline & Trauma context & \multicolumn{2}{c|}{ Total } \\
\cline { 1 - 3 } Year of residence & Non - Traumatic & Traumatic & \\
\cline { 1 - 4 } & 3.203 & 307 & 3.510 \\
\hline $\mathbf{2}$ & 3.677 & 135 & 3.812 \\
\hline $\mathbf{3}$ & 3.091 & 12 & 3.103 \\
\hline Total & 2.598 & 137 & 2.735 \\
\hline
\end{tabular}

Table 4

Complexity according to trauma context.

\begin{tabular}{|llll|}
\hline & Trauma context & \multicolumn{2}{c|}{ Total } \\
\hline Complexity & Non - Traumatic & Traumatic & \\
\hline Essential - Common & 10.052 & 430 & 3.510 \\
\hline Essential - Uncommon & 1.405 & 135 & 3.812 \\
\hline Complex & 1.112 & 26 & 3.103 \\
\hline Total & 12.569 & 591 & 13.160 \\
\hline
\end{tabular}

As for the subjective results, which illustrate the resident's perspective on learning and the ability to perform surgeries according to the complexity at the level that corresponds to their year of residence.

Graph 2 shows that $40 \%$ of residents fully agree that they feel confident to perform procedures that are at their level and $30 \%$ agree, whereas $20 \%$ of the respondents do not define a clear position regarding this item, while $10 \%$ disagree and none of the residents totally disagrees.

\section{Discussion}

The robustness of current surgical programs is still a matter of concern in surgery residency applicants [14]. Data from the United States show concerning deficiencies in the operative exposure of general surgery residents [6]. However, no optimal strategy is standardized given the difficulty of objective assessment of technical skill in surgery and the great variation in trainees experience [12]. To ensure consistent quality and educational standards, the use of a logbook registry is increasing among surgical trainee programs [12]; they constitute a useful tool to increase surgical exposure, reveal weak points of training [8], and enhance trainee-teacher communication [9]. However, it is still a non-validated proxy of proficiency, and surgical programs don't have it standardized [6]. 
An increasing disquietude in terms of resident operative experience, surgical training hours, and technical proficiency has been described in the literature, revealing direct relation with surgical exposure to common, uncommon, and complex procedures in a regular way during the residency [15]. Our findings suggest a regular number of procedures across the residency duration, among which essential procedures are performed mostly by first-year residents and there is a shift toward complex procedures with increasing residency year, similar to Malangoni et al results, where complex procedures increase through time until the last year of residency training [15]. Conversely, the increased number of subspecialty surgeries lead to a decrease in the quantity of complex procedures such as coloproctology, vascular and thoracic surgery compared to essential procedures led by the general surgeon [14].

Laparoscopic cholecystectomy (LC) was the most frequent procedure performed by our residents (7404), followed by appendectomy (1604), and hernia repair (1501), which compares to data reported by Malangoni et al and Cortez et al [2, 15]. Drake et al [16] reported a mean of 110 LC, 50 LA, and 30 laparoscopic groin hernia repairs, like those found in our study (246 LC, 53 LA, and 50 hernia repair). Malangoni et al and Cortez et al described complex procedures such as pancreatic and spleen resections are performed less than 10 times in contrast to 59 Whipple procedures, 10 distal pancreatectomies, and 11 splenectomies performed/assisted by our residents, showing a higher surgical exposure compared to what is reported in the literature $[2,15]$.

Trauma exposure in general surgery residency remains a complex concern for surgical educators, and program directors in the United States, Canada, and Europe [18]. Trauma training gap in general surgery residency led to the development of various focused courses in the surgical management of trauma, such as the "Advanced trauma operative management" (17). However, the implementation of multiple courses that could improve the confidence and judgment of the surgeon, does not change the fact that trauma education in general surgery residency it's a challenge. Multiple studies try to evaluate the surgical exposure of trauma complex situations and procedures [18]. Frequent trauma related procedures such as laparotomy and thoracotomy are still a matter of concern in different general surgery residency programs during all the surgical training, being performed less than 10 laparotomies and thoracotomies in trauma scenarios by more than $40 \%$ of residents, and more than $60 \%$ don't perform more than 10 vascular procedures in trauma circumstances [18]. Our results showed a significant trauma-related procedures exposure during all residency training accounting for almost $5 \%$ of all procedures performed including more than 10 laparotomies, thoracotomies, pericardial windows, and each including more than 25 trauma-related thoracostomies performed by young surgeons in their first year as surgery residents. In terms of total trauma-related procedures, Malangoni et al reported a mean of 35 procedures during training lower numbers compared to 591 trauma-related procedures performed by our population which include: thoracic (194), abdominal (138) and vascular ( $n=33)$; This data reflects the high trauma volume, and exposure of each resident compared with experience reported in the literature [19], representing a positive impact in self-confidence in trauma management of general surgeons who graduated from our program. 
The operative experience of surgical senior trainees has been published in the United Kingdom and Ireland [20]. Besides that, few studies around the world show the operative experience of each year of residency [6], and these experiences should be evaluated to analyze the surgical exposure of residents. Lonergan et al [6] describe their experience using a web-based logbook to analyze the surgical experience of general surgery residents and orthopedics; identifying common surgical procedures, and a gap in surgical training in his own program like the objectives of our logbook, seeking to evaluate the homogeneity of general surgery residents during their training. Residents' perspective of the log-book method as a tracking tool for their surgical exposure was evaluated, showing a $90 \%$ of satisfaction, and more than $70 \%$ of confidence in surgical experience based on the year of residence, revealing how this method is perceived as a cornerstone in each resident educational process throughout residency training.

Among limitations is the retrospective nature of the study, underreported secondary procedures that could vary the results, and inclusion of only one residency program. Nonetheless, even if only one residency program was included, the number of registered procedures in a 1 year is not insignificant.

\section{Conclusions}

Web based logbooks are a feasible method to follow operative experience in general surgery residents, by keeping track of the procedures, its complexity, and trauma context. General surgery residents in our program seem to feel confident to perform surgical procedures appropriate for their year of residency. Nevertheless, there is no consensus regarding the best way to measure resident experience and meanwhile we keep relying on proxies.

\section{Abbreviations}

- SCORE: Surgical Council of Resident Education

- LC: Laparoscopic cholecystectomy.

- LA: Laparoscopic appendectomy

\section{Declarations}

\section{Ethics approval and consent to participate}

Followed ethical committee of institution (Hospital Universitario Mayor Méderi), and informed consent of all participants. Available by request.

\section{Consent for publication}

Not applicable.

\section{Availability of data and material}


Available by request, contact corresponding author.

\section{Competing interests}

No conflict of interest to declare.

\section{Funding}

The present study did not receive any funding

\section{Authors' contributions}

The authors: FG, LR, CR, MV, DV, GL, RN, DC Participate in the conception of the idea, manuscript edition, manuscript correction, data recollection and analysis. All authors have read and approved the manuscript.

\section{Acknowledgements}

To our patients.

\section{Provenance and peer review}

Not commissioned, externally peer-reviewed

\section{References}

1. Dolmans D, Schmidt A, van der Beek J, Beintema M, Gerver WJ. Does a student log provide a means to better structure clinical education? Med Educ. 1999 Feb;33(2):89-94. doi: 10.1046/j.13652923.1999.00285.x. PMID: 10211257.

2. Cortez AR, Katsaros GD, Dhar VK, Drake FT, Pritts TA, Sussman JJ, Edwards MJ, Quillin RC 3rd. Narrowing of the surgical resident operative experience: A 27-year analysis of national ACGME case logs. Surgery. 2018 Sep;164(3):577-582. doi: 10.1016/j.surg.2018.04.037. Epub 2018 Jun 19. PMID: 29929755

3. Reames BN, Ghaferi AA, Birkmeyer JD, Dimick JB. Hospital volume and operative mortality in the modern era. Ann Surg. 2014 Aug;260(2):244-51. doi: 10.1097/SLA.0000000000000375. PMID: $24368634 ;$ PMCID: PMC4069246.

4. Tschudi P, Bally K, Isler R. One-on-one tutorials in private practices and clinics: four years of experience in Basel, Switzerland. Med Teach. 2003 Sep;25(5):537-43. doi: 10.1080/0142159031000136734. PMID: 14522678.

5. Dunnington G. Uneven operative experience in surgical training: a call for action. Ann Surg. 2009 May;249(5):725-6. doi: 10.1097/01.sla.0000348652.08671.1f. PMID: 19387301.

6. Lonergan PE, Mulsow J, Tanner WA, Traynor O, Tierney S. Analysing the operative experience of basic surgical trainees in Ireland using a web-based logbook. BMC Med Educ. 2011 Sep 25;11:70. 
doi: 10.1186/1472-6920-11-70. PMID: 21943313; PMCID: PMC3189901.

7. Díaz, C. et al. “Libro informático del residente de cirugía: Un paso adelante.” Cirugia Espanola 93 (2015): 651-657.

8. Chu TS, Chang SC, Hsieh BS. The learning of 7th year medical students at internal medicalevaluation by logbooks. Ann Acad Med Singap. 2008 Dec;37(12):1002-7. PMID: 19159032

9. Helenius I, Sinisaari I, Hirvensalo E, Remes V. Surgical procedure skills of graduating medical students: effects of sex, working, and research experience. J Surg Res. 2002 Feb;102(2):178-84. doi: 10.1006/jsre.2001.6310. PMID: 11796016.

10. Patil NG, Lee P. Interactive logbooks for medical students: are they useful? Med Educ. 2002 Jul;36(7):672-7. doi: 10.1046/j.1365-2923.2002.01163.x. PMID: 12109990.

11. Tschudi P, Bally K, Isler R. One-on-one tutorials in private practices and clinics: four years of experience in Basel, Switzerland. Med Teach. 2003 Sep;25(5):537-43. doi:

10.1080/0142159031000136734. PMID: 14522678.

12. Schüttpelz-Brauns K, Narciss E, Schneyinck C, Böhme K, Brüstle P, Mau-Holzmann U, LammerdingKoeppel M, Obertacke U. Twelve tips for successfully implementing logbooks in clinical training. Med Teach. 2016 Jun;38(6):564-9. doi: 10.3109/0142159X.2015.1132830. Epub 2016 Feb 3. PMID: 26841068; PMCID: PMC4926785

13. Mutabdzic D, Bedada AG, Bakanisi B, Motsumi J, Azzie G. Designing a contextually appropriate surgical training program in low-resource settings: the Botswana experience. World J Surg. 2013 Jul;37(7):1486-91. doi: 10.1007/s00268-012-1731-9. PMID: 22851149.

14. Bell RH Jr, Biester TW, Tabuenca A, Rhodes RS, Cofer JB, Britt LD, Lewis FR Jr. Operative experience of residents in US general surgery programs: a gap between expectation and experience. Ann Surg. 2009 May;249(5):719-24. doi: 10.1097/SLA.0b013e3181a38e59. PMID: 19387334.

15. Malangoni MA, Biester TW, Jones AT, Klingensmith ME, Lewis FR Jr. Operative experience of surgery residents: trends and challenges. J Surg Educ. 2013 Nov-Dec;70(6):783-8. doi:

10.1016/j.jsurg.2013.09.015. Epub 2013 Sep 26. PMID: 24209656.

16. Drake FT, Aarabi S, Garland BT, Huntington CR, McAteer JP, Richards MK, Zern NK, Gow KW. Accreditation Council for Graduate Medical Education (ACGME) Surgery Resident Operative Logs: The Last Quarter Century. Ann Surg. 2017 May;265(5):923-929. doi:

10.1097/SLA.0000000000001738. PMID: 28398961.

17. Jacobs LM, Burns KJ, Kaban JM, Gross RI, Cortes V, Brautigam RT, Perdrizet GA, Besman A, Kirton O. Development and evaluation of the advanced trauma operative management course. J Trauma. 2003 Sep;55(3):471-9; discussion 479. doi: 10.1097/01.TA.0000059445.84105.26. PMID: 14501889.

18. Barmparas G, Navsaria PH, Dhillon NK, Edu S, Margulies DR, Ley EJ, Gewertz BL, Nicol AJ. The gap in operative exposure in trauma surgery: quantifying the benefits of an international rotation. Surg Open Sci. 2019 Oct 25;2(1):46-50. doi: 10.1016/j.sopen.2019.09.003. PMID: 32754707; PMCID: PMC7391879. 
19. Engels PT, Versolatto A, Shi Q, Coates A, Rice TJ. Cause for concern: Resident experience in operative trauma during general surgery residency at a Canadian centre. Can Med Educ J. 2020 Dec 7;11(6):e54-e59. doi: 10.36834/cmej.69323. PMID: 33349754; PMCID: PMC7749680.

20. Morris-Stiff G, Ball E, Torkington J, Foster ME, Lewis MH, Havard TJ. Registrar operating experience over a 15-year period: more, less or more or less the same? Surgeon. 2004 Jun;2(3):161-4. doi: 10.1016/s1479-666x(04)80078-7. PMID: 15570819.

21. Agha R, Abdall-Razak A, Crossley E, Dowlut N, losifidis C and Mathew G, for the STROCSS Group. The STROCSS 2019 Guideline: Strengthening the Reporting of Cohort Studies in Surgery. International Journal of Surgery 2019;72:156-165.

\section{Figures}

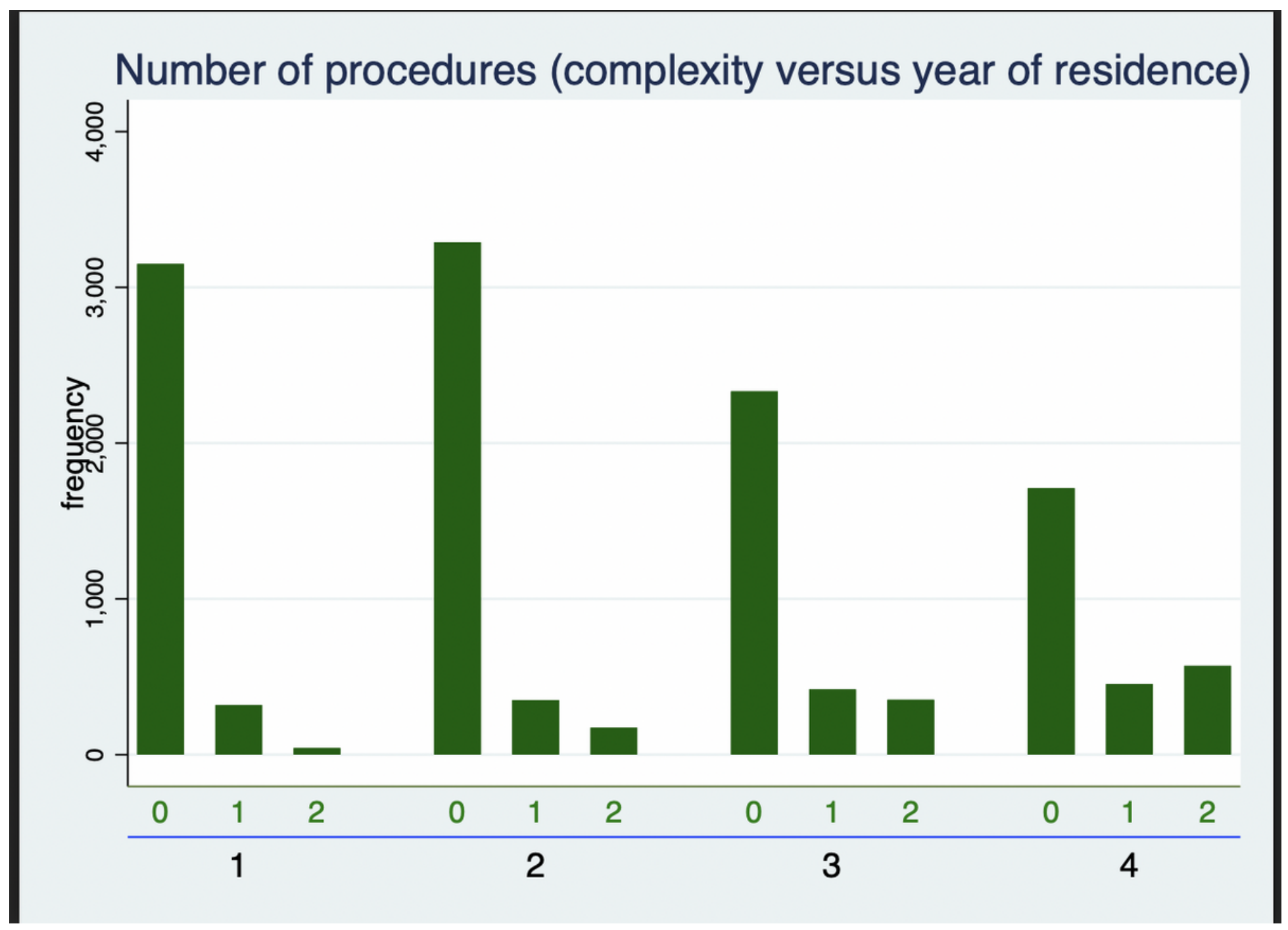

Figure 1

Graph 1. Complexity versus year of residence 


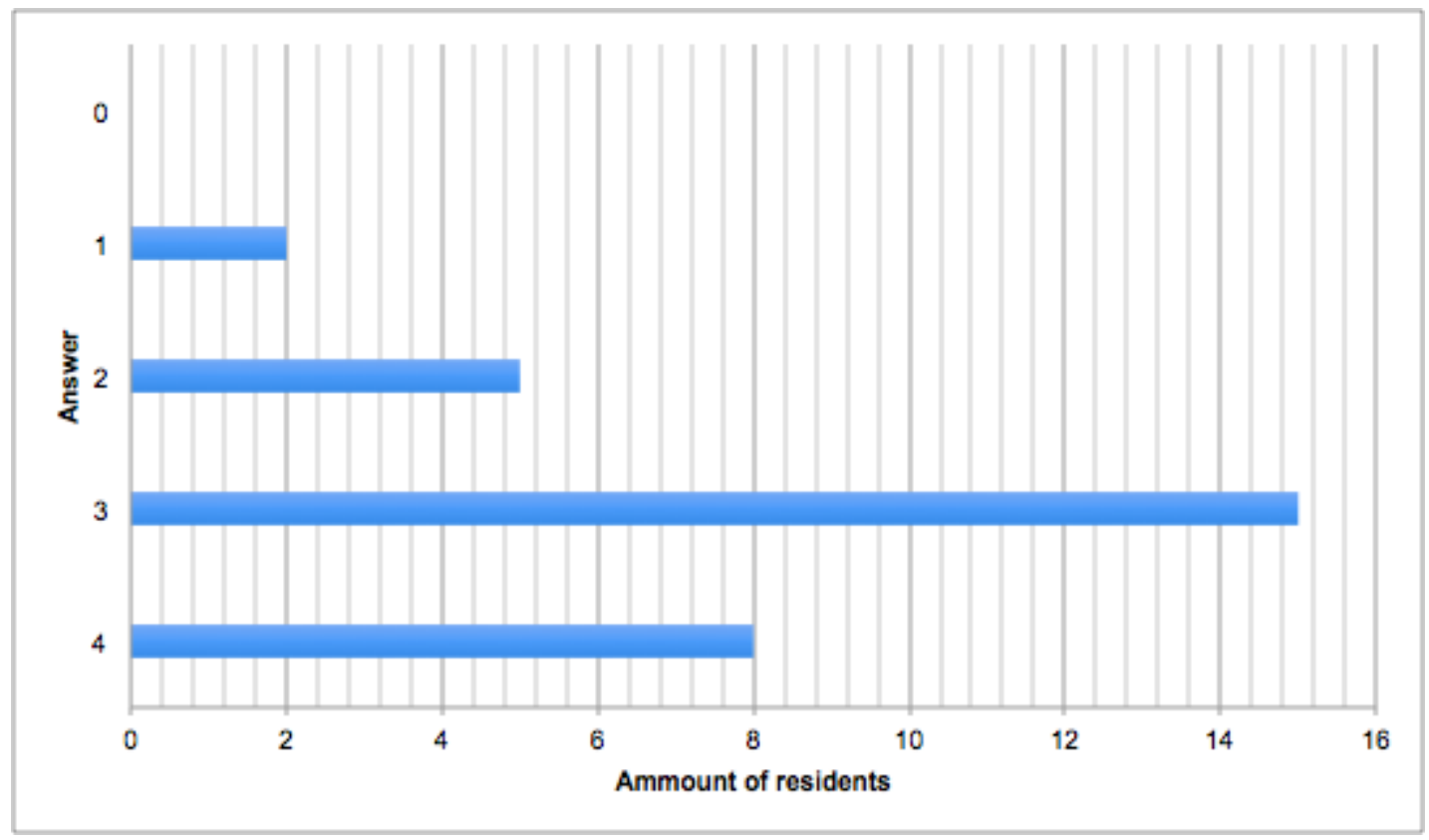

Figure 2

Graph 2. Survey: Do you feel confident performing procedures according to your residence year?

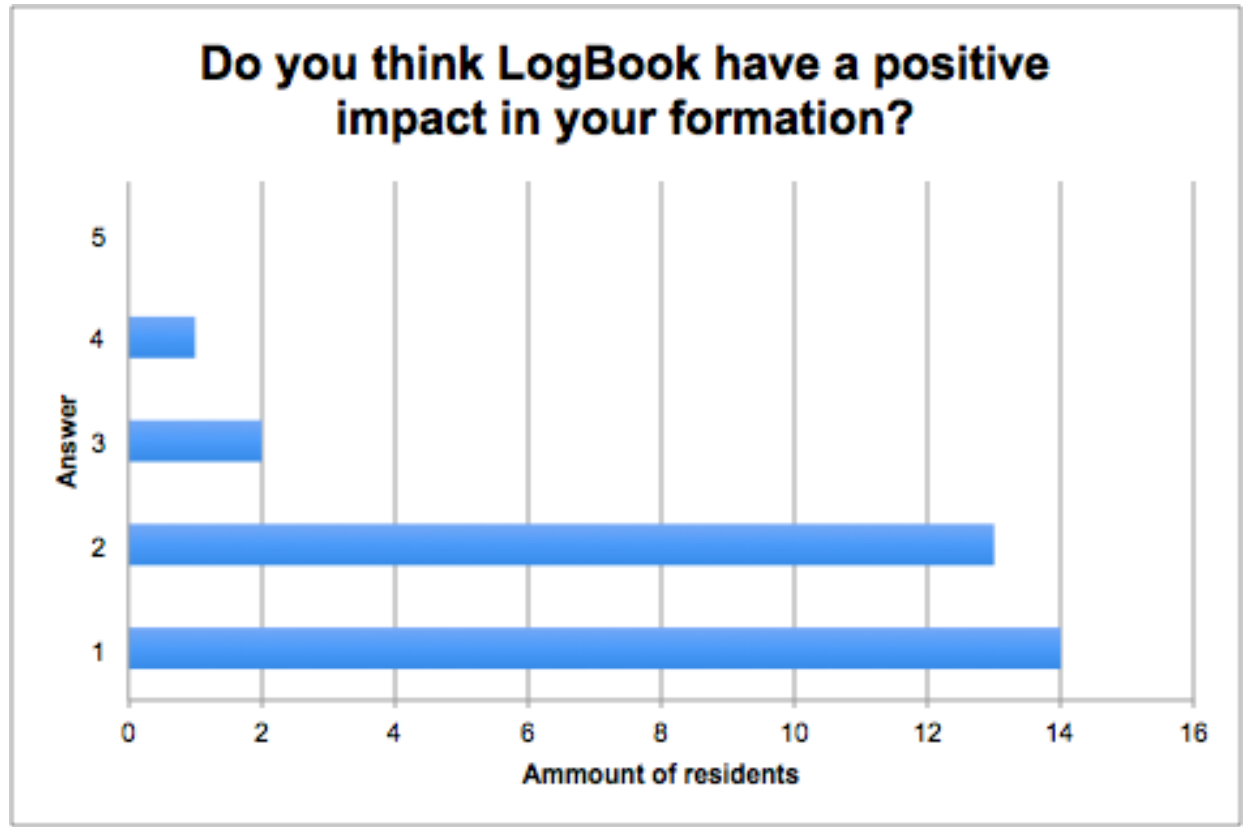

Figure 3

Graph 3. Survey: Do you think log book have a positive impact in your formation? 